\title{
Recovery and Cultural Values: On Our Own Terms (A Dialogue)
}

\author{
Justine Keen and Richard J. Shaw
}

\subsection{Introduction}

The dialogue in this chapter is about recovery in the sense of achieving a good quality of life as defined by what is important to (i.e. the values of) those concerned rather than by professional and service delivery priorities [1, 2]. The speakers, Justine and Richard, recorded their discussion live. They met in an informal environment and shared their experiences entirely unscripted.

At that time, they had no expectation of the dialogue being published beyond being a contribution to the work on co-production of a local group. Yet, the themes that emerge reflect a number of key ways in which cultural values may impact positively or negatively on recovery from severe mental ill health issues. These factors are given below with subheadings. Although not part of the original dialogue, the subheadings were agreed and introduced through a co-writing process in which the speakers themselves had an equal voice with the editors.

The factors identified as influencing recovery - the negative impacts of homelessness, loss of control over one's own life, plain discrimination, and the positive impacts of a home, friends, and a role in life-are not new. Indeed, it is a tragedy of contemporary approaches to mental health that these factors have been well recognised since the path finding work of the sociologists, Ann Rogers, David Pilgrim, and Richard Lacey nearly 30 years ago [3]. Just ask those concerned, their work showed, and it will be clear that what matters to people with severe long-term mental health problems is not more and not less than what matters to us all. As one of the speakers in the dialogue (Justine) put it in an earlier conversation and adapting a recipe for happiness widely attributed to Immanuel Kant: happiness requires 'something to do, somewhere to go, someone to love.'

\footnotetext{
J. Keen · R. J. Shaw $(\bowtie)$

Service User, Bristol, UK

(C) The Author(s) 2021

D. Stoyanov et al. (eds.), International Perspectives in Values-Based Mental

Health Practice, https://doi.org/10.1007/978-3-030-47852-0_23
} 


\subsection{The Dialogue}

In the dialogue that follows Richard's words are in black type and Justine's in bold italic.

\subsubsection{Street Culture}

When I came to Bristol, I had come directly out of the psychiatric unit in Preston who had amazingly worked out that there was nothing wrong with me without even talking to me.

\section{That sounds familiar}

So I was "hoofed" out of the psychiatric unit with no medicine, no help, nothing. So my dad gave me a couple of hundred quid and I decided I'd start again in Bristol. That turned out to be a mistake 'cause, er, when you're homeless in Bristol you're not treated very well. I have found it one of the worst places that I have been homeless; I have been homeless before. I was homeless in Blackpool, there are plenty of Bed and Breakfast in Blackpool, and they run 'em properly and so you have nothing to worry about. I was robbed and bullied by the owners of the Bed and Breakfasts who don't treat the homeless nicely even though we are paying them rent.

That seemed to be lost on him (the landlord) so I was illegally evicted by the Police, and I was forced to go and live in a flat with absolutely nothing for 2 months; if it hadn't been for me Mum putting food in a big box and putting it on DHL and sending it me down, I don't know what I would have done.

The owners stole a lot of my property, they stole my wallet, they stole the loan money I'd got from the DWP (Department of Work and Pensions) to buy property, they stole my wallet with that in it, and the Police said "we're not doing anything about it and this is a private matter" and I've said 'you're a Cunt"'-its not a very nice word but that's exactly what he said to me and he didn't do anything about it. So even the Police are not very nice to the mentally ill, and if these public servants can't be how is anybody going to learn?

Yep been there on different variants on a theme...

Yeah, um, I've had a mixed experience with the Police. I have to say that I had one very good experience with a Policeman who got me out of my flat before they had to break the door down.

Right...

He persuaded me to come out of the door, got my keys and locked it, gave me the keys and took me to hospital

Well that's a Policeman doing his job the right way.

Yes, and I've had the reverse experiences where....

Oh aye, they're not very nice to me, they're not very nice to me at all.

No, for instance I've been found drunk and incapable, but because they don't know why I am incapable they just put me in the cells, to sleep it off they think. And I got so lucky one time that I vomited and so they called the police doctor to examine me and he looked at my pupils and he said that there was something 
wrong, so they sent me to A\&E escorted and what they discovered a long time later after blood tests came back that I had actually taken, I didn't know how many because I had no way of counting, that I had taken paracetamol in a very severe overdose, and had I been left to sleep it off overnight I would have been dead in the morning. If I wasn't dead my liver and pancreas would have been shot.

They (the Police) should be ordered by the government to uphold the law and tell the truth, but you try getting them to do that. If they don't want to do that, then they bloody well won't. You can take a horse to water but you

Can't make it drink

Can't make it drink. But as I've said to the police, I'll take you to water, I can't make you drink, but unfortunately on this occasion, we'll drown you in it.

\subsubsection{Loss of Autonomy and Control}

Yes unfortunately, I have been down the old 'the only answer I've got is kill myself, at least I can control when I...'

Die

When I die, I can be in control of that

Same here-exactly that feeling... I can't control anything else in my life, everyone else is running my life telling me what to do, when to do it, how to do it, if to do it, not to do it.

Its horrible isn't it?

When you are in that bit of your life, all you want to do is to get the hell out of it ... you don't care how.

How

My life is different from that now. There are good things in it. Not perfect, it doesn't do.... I don't have many close friends. I have good friends but I don't have anybody I would pick the' phone up to and have a chat. Do you understand what I mean?

I do understand that. I'm very guarded when I am talking to people because I can say things and people can say "that's unbelievable, we don't believe you" I've had that, you know people will say "we don't believe you, you're lying-you're making it up"

I'd believe you every time Richard

I don't make anything up, my Dad was a flaming Magistrate and he didn't raise a fantasist, a liar or a peeing idiot.

No

\subsubsection{Unwarranted Assumptions}

But some people make these broad assumptions about the mentally ill and then dismiss us out of hand. 'Cause I know more than you because I'm a mental health professional, which is poppycock and balderdash, absolute poppycock and balderdash. 
Very good choice of phrases there Richard, and yes there is a large section of society that know next to nothing about mental illness except for maybe mild to moderate depression and anxiety, and that's what they think mental illness is. And they will campaign and place on their Facebook pages. And yes, it's important. I don't for a moment deny that mild to moderate anxiety and depression is extremely debilitating, extremely nasty, and I class those people as having a mental health condition.

They have

...but you take the next step along and start looking at things like whatever psychosis encompasses, whatever OCD, Obsessive Compulsive Disorder, encompasses; that's another serious mental illness.

And these are the ones that are ignored, and I would wish... Mind have tried... they have done a campaign but a lot of it was about mild to moderate anxiety and depression, but there were a couple of 'um short documentaries on their website about people coming into psychosis for the first time.

Mm... it's not nice

\subsubsection{The Fear Factor}

Like, one of the ones that really struck me for a personal reason was a lad who after his diagnosis no-one would leave their children alone in the room with him.

Yes, I had a friend who is sadly no longer with us ... um 'Andy', we'll call him; that's his name. He suffered from schizophrenia, we used to sit and talk, about our voices, and he'd tell me what they were saying. He had three young boys, and his voices were telling him to kill his children.

Ohhh Oh no

So he had spoken about this up [name of police station] on one of his things and then all hell broke loose.

It would

In the end, he was allowed to keep his children. He wouldn't hurt them; he loved them. It was obvious that he loved them enormously. He's like me, he's like you, he doesn't respond to what the voices say, and he wouldn't do it. He loved his kids.

\subsubsection{Self-Managing Our Voices}

It's fine to respond to the voices, it's not fine to do what the voices want. It's to attack myself in some way that would prevent me from doing what the voices want.

Well I just argue. You see, I don't think my voices are right in any way shape or form about anything that they say.

Mine are extremely persuasive

Mine are too. Go kill yourself Richard they say. 
Yep exactly, mine tell me to kill myself because I'm a paedophile. They tell me that I am a risk to children. That I shouldn't go near children. You know that I'm a bad person... you know all of that.

I know, I know, I live with it, it's a constant battle to keep your bloody pecker up with these lot.

Yes.

\subsubsection{To Be Happy}

But you see my ultimate goal... my ultimate goal is to achieve happiness in life.

Yeah

I think that's a reasonable objective and goal for everybody to achieve some modicum of happiness in life.

Yes to have during the day on average an hour when are sat there chilled and happy. Then you can deal with the rest of the day.

I do. I live on my own, and I am perfectly happy living on my own. If I want to socialise I can talk to my neighbours and go up the pub.

\subsubsection{Pub Culture}

\section{Could you say more about your mates at the pub.}

Yeah brilliant. I call on my mates up the pub. They all know me, good bunch of lads, they're all working hard. Builders, roofers, and people like that and they've all been really good to me. When I came to Bristol, I was completely on my own, I was so immersed in my psychological distress that I wasn't effectively communicating properly with anybody, and I actually found communicating very difficult because I was in such a state of mental distress, which was only made worse through the treatment of Bed and Breakfast owners, the Police, and NHS, and they really put me through the mill. I really thought "my life is over here."

Er so... I... I... I... had already been through several suicide attempts, the last one, the last time I attempted, I had to go and see a psychiatrist who wasn't very useful. I think he was a CPN. He wasn't very useful. Anyway, they weren't very useful and so I basically knew that my problem was my problem, and the only person that was going to resolve my problem was the person that is aware of my problem...

Which is you....

\subsubsection{The Culture of Mental Health Services}

Which is me. The people that should help me with the problem weren't listening to my problem. Too busy...

Filling in their forms by any chance? 
Yeah. Whitewashing over my problem. Saying it's not a problem, and its all in your head. That's absolute bloody rubbish, and it's a real problem.

Yes, and are you saying, like I am saying, "the voices I am hearing are real"

Well, they are real to me. I hear them, I appreciate nobody else does.

Well I never know, I can't tell... because I don't know if they are hearing them and pretending not to-to be nice to me.

No, nobody can hear inside your head apart from you. I'm telling you that now. Ears are not that clever.

I'm still unsure about mine

\subsubsection{Taking Back Autonomy and Control}

You see... I hate being told what I'm thinking because I am a believer that nobody knows that apart from the person that is doing the thinking.

That makes sense, that's you.

Nobody can tell me what I am thinking. You can ask me. You can enquire... but if you say "you're thinking this Richard"... No I am not thinking that at all. You are telling me conveniently so when you argue that I am thinking that. You are not listening to me.

Ahhh OK, OK That's making some sense to me. Your culture of how you deal with so-called professionals and your diagnosis is quite different from mine. I sort of (um), cave in to (um) what I've been told about what I have experienced.

It's almost as if sometimes it feels as though certainly with the police they pressurise you. Do this, do that, believe this, believe that.

Yeahh...

\subsubsection{And Being Listened to}

Y'know Until people are made to listen to mentally ill people and respond appropriately to their needs, we've successfully come up with a way of failing them.

Yeah...

I do feel let down on occasions certainly by the Police and the NHS and I do feel failed. It's almost as if the whole system is rigged against mentally ill people. Sometimes, it does seem to me that you got this inner battle within yourself. You know we are all responsible for ourselves, so we have some... We as mentally ill people have to be careful about our behaviour. What we're saying, where we're going, and make sure that we don't put ourselves in harm's way or danger.

Correct. I rarely go out when it's dark.

I don't at all

Even in the short days when it can go dark at 4:30. If I am out somewhere at that point I am heading home as fast as my little legs will carry me. 


\subsubsection{Pub Culture Again}

I mean going back to my mates in the pub. They're all good lads. They're all grown up, mature, working, and responsible adults. That's fine that pub during the day. But you wouldn't catch me drinking; well, I avoid drinking in there in an evening because you get all the young lads come in.

Uh Huh... and they tease you

Well, no, no they're alright. I get the odd comment, or I might get laughed at...but you know I have learned to accept in life that some people are just ignorant, and they are perfectly happy to stay ignorant.

In fact, if I ever get any aggravation, one of my mates warns them off!

\subsubsection{Management Culture and Leadership}

I know what I know, and I know enough; but you know nobody knows it all, and I don't think you can have too much knowledge. I think, think you can suffer from not having enough...but there is a lot to learn in this life and anyone who thinks they know it all and stops learning is stupid 'cause you can't know it all. There's an awful lot of things in this life that I don't know.

Life is immense in all its different ways and bits of knowledge. It's how you use what you've got and how you use it to expand in the right direction and in the right way. And for me it's about making the best use of limited resources, 'cause resources are not infinite.

No they're not... no they're not

The mental health services, not only are they poorly resourced, which is the first thing that is wrong, but the second thing is...they have tiers of middle management that I just, maybe naively... y'know I'll take an argument saying I'm wrong... but don't seem to do much other than manage people. Managers for managers? Y'know, why?

Well, I mean a lot of how I understand management is leadership. An important part of management is leadership. There has to be someone at the helm, nailing it, getting it right, leading from the front, setting an example, and everybody to raise their game.

Yes, level up not level down.

Sometimes, in this life, we are expected to dumb down our expectations to fall in line with the shoddy...

\section{What's available}

... the shoddy or the piss poor services that as you quite rightly just stated, are massively underfunded. You know, and it seems that we are palmed off with the second rate and shoddy when really that is not in the country's best interests to treat people like that.

No 'cause you treat somebody badly they expect they are bad... and when they expect that they're bad they're going to act bad. 


\subsection{Conclusions}

This dialogue makes uncomfortable reading for many of us. But the issues raised are key to understanding the impact of cultural values both positive and negative on recovery. On the negative side of the balance are prejudice and discrimination from many directions: landlords, the Police, members of the public, and services. This much - forcefully expressed in this dialogue from first-hand experience-is sadly all too familiar. Yet, there is also a positive side: one speaker's help from his family and later through companionship in his local Pub; the other had had on one occasion help from the Police.

It is important to acknowledge the balance here. Yes, despite many campaigns (MIND is mentioned at one point), people with severe long-term mental health conditions experience continuing discrimination. But there is also hope for recovery here. Hope not in expanded services as such (though both speakers emphasise the need for better funding) but in the initiatives of the speakers themselves in taking back control. It is when they regain control of their lives, when they take a stand against being told by professionals what is 'good for them', that they find their turning points towards recovery. What this means, though, is not simply independence but - as David Crepaz-Keay puts it in his story in chapter 22, "Three Points in Time: How Values and Culture Affected my Life, Madness and the People Around Me" "Alcohol Use Disorder in a Culture that Normalizes the Consumption of Alcoholic Beverages: The Conflicts for Decision-Making"-Inter-dependence. It is Richard's pub culture that gives him his 'hour of happiness' and it is Justine's lack of just such a group of friends that leaves a continuing gap in her life.

Acknowledgements We are grateful to the Bristol Co-production group for their continuing support and many kindnesses.

\subsection{Guide to Further Sources}

There are now extensive recovery resources available - please see Guide to Further Sources supplied by Waldo Roeg in his chapter 32, "Discovering Myself, a Journey of Rdiscovery" "Linking Science with People: An Introduction to Part IV, Science."

For a profile of the Bristol Co-production group, please go to: valuesbasedpractice.org/who are we/organisations (and scroll down to the Group's listing).

The work of the Bristol Co-production group on assessment in mental health is described in:

Fulford, K.W.M., Duhig, L., Hankin, J., Hicks, J., and Keeble, J. (2015) Valuesbased Assessment in Mental Health: The 3 Keys to a Shared Approach between Service Users and Service Providers. Ch 73, in Sadler, J.Z., van Staden, W., and Fulford, K.W.M., (Eds) The Oxford Handbook of Psychiatric Ethics. Oxford: Oxford University Press

For a short film recording the Group's experience of working together, please go to the Bristol Co-production group profile - see website above. 


\section{References}

1. Allott P. What is mental health, illness and recovery, Ch 1. In: Ryan T, Pritchard J, editors. Good practice in adult mental health, Good practice series 10. London: Jessica Kingsley Publishers; 2004.

2. Slade M, Amering M, Farkas M, Hamilton B, O'Hagan M, Panther G, Perkins R, Shepherd G, Tse S, Whitley R. Uses and abuses of recovery: implementing recovery-oriented practices in mental health systems. World Psychiatry. 2014;13:12-20.

3. Rogers A, Pilgrim D, Lacey R. Experiencing psychiatry: users' views of services. London: The Macmillan Press; 1993.

Open Access This chapter is licensed under the terms of the Creative Commons Attribution 4.0 International License (http://creativecommons.org/licenses/by/4.0/), which permits use, sharing, adaptation, distribution and reproduction in any medium or format, as long as you give appropriate credit to the original author(s) and the source, provide a link to the Creative Commons license and indicate if changes were made.

The images or other third party material in this chapter are included in the chapter's Creative Commons license, unless indicated otherwise in a credit line to the material. If material is not included in the chapter's Creative Commons license and your intended use is not permitted by statutory regulation or exceeds the permitted use, you will need to obtain permission directly from the copyright holder. 